\title{
DIFÍCIL Y SIN APOYOS POLÍTICOS La Representación por España de los intereses japoneses durante la Guerra del Pacífico
}

\author{
Florentino Rodao
}

Una de las facetas más calladas dentro de las relaciones internacionales son las acciones humanitarias, y dentro de las relaciones hispano-japonesas quizás el momento más importante en este aspecto fue la protección por España de los intereses japoneses durante la Guerra del Pacífico. Desde su estallido el 7 de diciembre de 1941 hasta la renuncia hispana a esta defensa de los intereses japoneses, el 21 de marzo de 1945, pasaron cuatro años en los que el Imperio del Sol Naciente dependió en gran medida de la acción de los españoles en esta faceta tan importante para Tokio.

El marco para la acción española eran los acuerdos de carácter internacional establecidos con el objeto de reglamentar unos procedimientos humanitarios, en situaciones tan escasamente dadas a estas actitudes como son en las guerras. Los acuerdos habían sido actualizados en Ginebra, en 1929, basándose en la experiencia de la I Guerra Mundial, estableciendo la obligatoriedad de ayudar al personal militar herido o enfermo y los derechos de los prisioneros de guerra. Además, también se acordó el establecimiento de potencias neutrales - que serian nombradas por los países en guerra- para salvaguardar los intereses nacionales en territorio enemigo. Entre otras tareas, los representantes designados por las naciones enemigas tendrían derecho a inspeccionar las condiciones de los prisioneros y su derecho a un tratamiento humano.

Japón necesitó de estas naciones neutrales para cuidar de sus nacionales en territorio enemigo. Además de Estados Unidos y el Reino Unido, se vio envuelto en multitud de rupturas diplomáticas y declaraciones de guerra; en el continente americano, unos gobiernos declararon inmediatamente la guerra a Japón y al resto de los países del Eje (Costa Rica, la 
República Dominicana y los pequeños países de Centroamérica declararon la guerra a Tokio sólo una semana después del ataque a Pearl Harbor) mientras que otros se limitaron en un principio a romper las relaciones (Cuba, Venezuela, Brasil o México). La actitud neutral fue encabezada en este continente por Argentina, al declarar el 9 de diciembre de 1941 que cumpliría con sus obligaciones internacionales, es decir, que seguiría las relaciones con el Eje. No obstante, esta postura quedó aislada tras la Conferencia de Río de Janeiro de fines de enero y principios de febrero de 1942, puesto que quedaron únicamente este país y Chile sin romper relaciones ni declarar la guerra a Japón, en una resistencia a la presión de Washington para adoptar una actitud más dura, que pudo durar poco tiempo. Aún así, ni siquiera la posición de estos dos países fue de estricta neutralidad, pues Santiago y Buenos Aires se unieron a los principios de "Solidaridad Continental» aprobados en la Conferencia y Washington -al contrario de lo que ocurrió con el resto de los implicados en la II Guerra Mundial- nunca recibió en estos países el estatuto de "País Beligerante".

Tokio necesitaba designar potencias neutrales y para ello solicitó a cuatro países proteger sus intereses en el mundo: Portugal, España, Suiza y Suecia. Entre ellos, fue España el país que tomó esta tarea en el continente americano, a excepción de Portugal, que se encargó de México y Guatemala '. Así, Madrid tomó poco después del comienzo del conflicto la representación de los intereses en Estados Unidos, Canadá, Colombia, Cuba, Ecuador, Panamá, San Salvador y Venezuela. Poco después, lo hizo con Uruguay, Bolivia, Brasil y Perú ${ }^{2}$. No es difícil imaginar que el gobierno español tuvo el encargo más difícil, puesto que se quedó a cargo de representar los intereses japoneses en los paises donde habia colonias niponas más importantes, como Perú y Brasil y donde, además, interesaba más esa labor, como era Estados Unidos, "el país en el que nuestros intereses son mayores y sobre el cual nosotros estamos más profundamente preocupados" ${ }^{3}$.

Para un esquema de las fechas y de los paises que representaron los intereses de Japón, incluyendo también las fechas de las declaraciones de guerra, ver OTA ICHIRō.- Daitōa Senso. Senï gaikö (La Guerra del Gran Asia Oriental. Diplomacia en tiempo de Guerra), en Col. NiHON CAIKōshi (Historia Diplomática de Japón), Vol. 24. Tokio, 1970, págs. 20-34. La lista contiene algunas contradicciones y errores de escasa importancia.

Archivo del Ministerio de Asuntos Exteriores (AMAE), Legajo (Leg.) 1562, expediente (exp.) 10. Informe sin firma al Ministro Serrano Suñer, Madrid, 4-II-1942.

3 Telegrama (Tel) de Tōgō a Suma, en Magic Summaries (MS, copia en National Archives and Records Administration (NARAS), Washington, Record Group (RG) 457, National Security Agency) de 7-VI-1942. Sobre las colonias niponas en América, ver Yanaguioa TOSHIO Y Ma Dolores Rodriguez del Alisal.- Japoneses en América. Colección América, Crisol de Pueblos. Madrid, Mapfre, 1992. págs. $1 \uparrow 7-119$ y passim. 
La razón por la que España fue elegida por Japón para una tarea tan importante fue una mezcla motivaciones de carácter técnico y político, probablemente prevaleciendo el segundo. Dentro de las razones técnicas, hubo de influir el hecho que España tenía la red diplomática más numerosa y extendida en los países americanos para poder desarrollar esa tarea; algo que hubo de ser muy importante, pues una buena parte de los emigrantes nipones instalados en América Latina vivían en áreas rurales. Por otro lado, ya había una experiencia anterior de representación de intereses, pues Madrid había representado los intereses de Japón en Alemania durante la I Guerra Mundial.

Dentro de los aspectos políticos, la amistad mutua y la identificación anticomunista también hubo de influir fuertemente. Se suponía que los funcionarios españoles habian de ser más favorables a los intereses de Japón como miembro del Eje, al que los españoles estaban tan cercanos y de hecho Madrid ya estaba actuando como pais protector de Italia y Alemania desde el comienzo de la guerra en Europa. No es extraño que este hecho se tomara en cuenta y esa amistad también fue considerada por Estados Unidos para no encargar a España la protección de sus intereses en Japón, aunque fue uno de los países apuntados por el Embajador Crew tras ser detenido en la Embajada norteamericana en Tokio ${ }^{4}$. Además, más allá de estas amistades políticas, a través del primer telegrama sobre la cuestión enviado a Estados Unidos, podemos obtener pistas que permiten pensar en una utilización de esa representación de los intereses japoneses como canal para la recolección de información confidencial en dirección a Tokio:

"A petición gobierno japonés, España acepta encargarse sus intereses en éste país. Sirvase vd. comunicarlo ese gobierno, ordenando nuestros cónsules de carrera háganse cargo respectivos Consulados japoneses. Informe urgentemente ciudades donde exista consulado japonés y no español. [1 palabra perdida] para respectivas zonas posibilidad incluirlas en jurisdicciones consulares españolas. Gobierno japonés encarece especialmente protección total Embajada y Consulados Nueva York, San Francisco, Chicago, Los Angeles, Portland, Seattle, Nueva Orleans y Boston. Propóngame urgentemente personal y presupuesto considere necesario para cumplimiento nuevas funciones, indicando si en respectivas colonias existen españoles de confianza no significados ante autoridades norteamericanas

4 Se escogió a Suiza. La razón por la que Joseph Crew habia propuesto a España pudo ser por su amistad con el Ministro en Tokio, Santiago Méndez de Vigo, opuesto a la línea de Serrano Suñer. Ver también ConBETt, P. Scort.- Ouiet Passages, Kent, Ohio, 1987, p. 42, cita una entrevista con James E. Keeley, quien trabajó en la División Especial del Departamento de Estado norteamericano, encargada de la representación de intereses, durante la Guerra Mundial. 
como "quintacolumnistas», cuya colaboración pueda utilizarse en cumplimiento esta misión de alto interés nacional» ${ }^{5}$.

Multitud de tareas esperaban a los diplomáticos españoles una vez que se decidió aceptar el encargo japonés. Tras la entrada de los Estados Unidos en el conflicto, las medidas contra los súbditos del Eje se produjeron inmediatamente y alrededor de 3.000 alemanes e italianos fueron detenidos por el FBI, tras discernir entre los partidarios y entre los opuestos a las ideas totalitarias. Sin embargo, con los japoneses no hubo tal esfuerzo de selección y la gran mayoría de la colonia, más de 60.000 personas, tanto de primera como de segunda o tercera generación, fueron internados en alejados Centros de Realojamiento de Guerra (War Relocation Center), sin discriminación de sus ideas políticas, en parte por temor a que pudieran suministrar información a Tokio ${ }^{6}$. En el resto del continente se siguieron las medidas adoptadas en Estados Unidos, con mayor o menor dureza. Canadá y México, por ejemplo, tomaron también medidas contra los japoneses casi simultáneamente a las de los Estados Unidos, Perú creó un centro de detención para japoneses por su propia cuenta, enviando algunos de ellos a Estados Unidos, Cuba estableció un programa de detención con Washington y en Venezuela, igualmente, fueron deportados 300 japoneses que habian entrado ilegalmente. Como vemos, fue dispuesta ocasionalmente la evacuación de los súbditos japoneses a los Estados Unidos, así como la censura en sus comunicaciones o el bloqueo de sus fondos bancarios. No obstante, la principal comunidad japonesa en Sudamérica, Brasil, con alrededor de medio millón de personas, no sufrió grandes problemas y pocos de ellos fueron molestados.

Los funcionarios españoles, desde un principio, hubieron de visitar los campos de internamiento y detención y realizar giras de inspección, cada cuatro o seis semanas, para comprobar las condiciones de estancia. Quizás el trato fue peor en Latinoamérica que en el norte del continente, precisamente porque a los maltratos se sumaron los traslados fuera de sus fronteras, tanto a Estados Unidos como dentro de la región; por ejemplo, el

5 AMAE, Leg. 1913, exp. 5. Tel 333 de Ministro de Asuntos Exteriores (Mae) a Embajada en Washington, Madrid, 12-XI1-1941. Este es uno de los pocos documentos que quedan de la carpeta referente a Japón de la sección Gabinete del Ministro del periodo en que Ramón Serrano Suñer estuvo al frente del Ministerio de Exteriores español. Los funcionarios norteamericanos lo sospecharon, según le cuentan posteriormente a Corbett, op. cit., pág. 44 (Entrevista a James H. Keeley).

6 Sobre los programas de internamiento, ver WEGLYN, MiCHI: Years of Infamy, New York, 1976 o LeHMAN, R. ANTHONY: Birthright of Barbed Wire, Los Angeles, 1970. AMAE, Leg. 1913, exp. 5. Tel 493 de Cárdenas a Mae. Washington, 19-X|1-1942. Sobre la amenaza estratégica que podian suponer, ver The Times, Londres, 23-I-1942. 
Campo de Internamiento "Balboa", en Panamá, reunió los internados de este país y de Costa Rica ${ }^{7}$. En otros casos, como en Bolivia, el embajador español hubo de luchar duramente para evitar la promulgación de una orden y evitar la evacuación de todos los súbditos del Eje del país ${ }^{8}$. En ocasiones, se contrataron a japoneses para cubrir estas tareas, los cuales trabajaron también como un canal de comunicación con Tokio informando de los problemas de la comunidad. En Madrid, por su parte, para cubrir específicamente éstas tareas, se creó el 29 de enero de 1942 la Oficina Central de Protecciones en el Ministerio de Asuntos Exteriores.

Los resultados de la labor española se pudieron ver pronto y en febrero de 1942 los diplomáticos españoles en Estados Unidos ya habian visitado todos los centros de realojamiento de la costa oeste. El 27 de marzo, por ejemplo, llamaron la atención sobre la diferencia entre la lista de detenidos del FBI y la de la Cruz Roja y, además, inquirieron sobre el carácter de la detención y sobre si se arrestaría también a los estudiantes. Las solicitudes españolas para investigar las condiciones del internamiento generalmente eran cuestionadas por los norteamericanos —quejándose de la imposibilidad para los diplomáticos suizos de hacer lo mismo en Asia Oriental con los detenidos estadounidenses- ${ }^{9}$ pero de alguna forma su labor era facilitada por el temor a un reciprocidad de Tokio caso de recibir un informe desfavorable sobre las condiciones de trato de sus nacionales ${ }^{10}$.

Quizás la labor más llamativa de esta labor fueron los dos intercambios de civiles entre Estados Unidos y Japón durante la Guerra, organizados conjuntamente por Suiza y España, uno en el mes de junio de 1942 y otro en septiembre de 1943. Los japoneses fueron acompañados por un secretario de la Embajada española en Washington y esa participación fue utilizada propagandísticamente por Madrid ${ }^{11}$.

La faceta más complicada, por su parte, era la derivada de la pobreza de recursos que generó la ola antijaponesa entre los no-detenidos. Las Listas Negras de negocios japoneses resultaron desastrosas para su

\footnotetext{
7 AMAE, Leg. 1134, exp. 3. Tel de Manuel Oños, Cónsul de España, a Mae, Panamá, 21-lil1942. Informa sobre 185 hombres internados.

8 Tel de Tomii (Embajador japonés) a Tōgō (Ministro de Exteriores), Buenos Aires. En MS de 10-VI-1942.

9 En Filipinas, por ejemplo, Japón no reconoció el papel protector de Suiza, argumentando que al ser un territorio conquistado no estaba cubierto por el sistema de protección. La argumentación era correcta técnicamente.

10 Corbett, op. cit., pág. 46.

11 "Hoy comienza el canje de japoneses y americanos con la intervención de España", Arriba, por Luciano CeJuela, 4-VI-1942.
} 
bienestar ${ }^{12}$ y además, sufrieron bloqueos de fondos en los bancos, pérdidas de trabajos, internamientos forzados y destrucción en sus propios negocios. Precisamente estas dificultades motivaron la primera demanda hispana al gobierno de los Estados Unidos, el 22 de enero de 1942, solicitando organizaciones caritativas para ayudar con dinero a los japoneses ${ }^{13}$.

Esta necesidad de ayuda financiera hizo que España recurriera también al gobierno japonés, señalando que entre los japoneses internados y sus familias habia una necesidad de inmediata ayuda financiera ${ }^{14}$. Tokio, en un principio, estaba en contra de las remisiones de dinero, ya que la Convención de Ginebra afirmaba que las provisiones para los internados y sus familias debían ser provistos por el país donde estuvieran instalados ${ }^{15}$. No obstante, tras comenzar los españoles a ayudar en la representación de intereses, se dispusieron fondos para ello, aunque teniendo crecientes dificultades ${ }^{16}$.

No está claro de dónde salian estas cantidades, pero sí hay constancia que Tokio hizo lo posible para enviar el dinero que se necesitaba, por medio de perlas o de gemas preciosas, o bien usando 500.000 Dólares en metálico dejados en la Embajada en Washington ${ }^{17}$. El destino final del dinero que se quiso o se hizo llegar a España es difícil que se conozca, puesto que mientras en ocasiones fue usado para ayudar financieramente a los súbditos japoneses, en otras también pudo ser usado para las actividades de espionaje. Así, los Estados Unidos siempre hicieron lo posible por evitar los envíos a los españoles y gracias a su decodificación de las comunicaciones diplomáticas, tanto españolas como japonesas, fueron descubiertas algunas de estas operaciones. El seguimiento de las operaciones fue hecho por el servicio de contra-inteligencia para evitar la llegada de dinero a los funcionarios españoles ${ }^{18}$. Hubo de haber otras operaciones con éxito de envío de dinero y, por ejemplo, la Legación en Brasil

12 Tel de Yamagata (Ministro Japonés) a Tōgō. Santiago de Chile, 10-IX-1942. En MS de 12-IX-1942;

13 CORBETt, ibid., p. 47.

14 Suma, pretendidamente recibido de Cárdenas, a Tôgô. MS 3-VI-1942.

15 Tōgō a Suma, en MS de 6-VI-1942.

16 informe de Contra-inteligencia aparecido en MS de 21-XII 1943.

17 La cuestión de cómo el dinero fue usado no ha sido aún investigado. Algunos archivos contienen documentación sobre ello en AGA, AE, Cajas $8476,8703,8713$ y 8714 . Para la representación de intereses en Nueva Orleans, con un muy buen inventario, ver la Caja 11746.

18 Tógó a Suma, Tokio, 28-XII-1942, en MS de 9-1-1943. Sobre ello, ver KREBS, GERHARD, Spanien und Japan, 1936-1945, Tokyo, OAG, 1990, p. 37. También, MS de 3-V-1942, 15-XII1942, 14-II1943 y 22-V-1943. Ver también mi “España, espiada por Estados Unidos en la II Guerra Mundial", en Historia 16, Año XX, núm. 233, sept. 1995, pp. 17-24. 
tenía aún una gran cantidad de fondos cuando cesó en su encargo, en $1945^{19}$.

Esta dificultad para poder ayudar a los necesitados nos muestra claramente las dificultades que hubo para ejercer esta función, aunque no estuviera sino indirectamente relacionada con la marcha de los acontecimientos, puesto que los afectados eran población civil. Además de la dificultad de enviar dinero, estuvieron las presiones que tanto japoneses como americanos trataron de ejercer sobre los funcionarios españoles para sus propios propósitos. Como ya hemos visto, los funcionarios de Estados Unidos intentaron presionar a los españoles como una forma de conseguir que Tokio permitiera a los suizos las visitas a sus detenidos en los territorios ocupados por Japón (Suiza, como ya hemos señalado, sólo podía visitar detenidos en la metrópoli, además de en Shanghai, pero no en otros lugares).

Siguiendo con las dificultades que encontraron los españoles para ejercer la acción humanitaria, los gobiernos americanos intentaron limitar la acción de los españoles y hasta finales de 1942 no se comenzó a saber entre los internados en Estados Unidos que podían expresar sus quejas al gobierno japonés valiéndose de la mediación de los cónsules españoles. Aun así, para un detenido o «realojado» podía ser comprometedor solicitar la intervención de alguna potencia neutral en cuanto podia ser estigmatizado como pro-eje y ello significaría un mayor control hacia él ${ }^{20}$. Por otro lado, Estados Unidos intentó acotar las funciones de los españoles como, por ejemplo, limitar su campo de actuación a los japoneses de primera generación, tal como señala el siguiente memorándum enviado a los directores de los Centros de Realojamiento: «España es la potencia protectora de los intereses japoneses en Estados Unidos [...] a este respecto, tiene que entender que Estados Unidos no considera que los evacuados en los campos de realojamiento hayan sido internados [...] Básicamente, el representante español, tiene su función con extranjeros, es decir, los súbditos japoneses en este caso..." ${ }^{21}$.

Por su parte, los japoneses, tanto los internados en Estados Unidos como el gobierno de Tokio, también intentaron usar el «canal español» para

19 AMAE, Leg. 3195, exp. 25. Tel de Garcia Conde (Ministro Español) a Mae, Rio, 6-IV-1945. La Embajada española en Brasil también sirvió para transferencia de dólares estadounidenses para otros paises del subcontinente. MS de 15-VI-1942.

20 NARS, RG120. Declaraciones de un informante recogidas en carta del Comandante Wallace Wharton a E.M. Rowalt (War Deputy Director), sin techa, cit. en Weglyn, op. cit., p. 120.

21 University Research Library, University of Calitornia at Los Angeles (UCLA). Archivos del Centro de Manzanar, 1942-1946. Memorándum de Dillon S. Myes a Todos los Directores de Proyectos, 9-XI1-1942, cit. en Weglyn, op. cit., pág. 120. 
transmitir mensajes más allá de lo humanitario o para infundir mensajes propagandísticos entre las colonias arrestadas ${ }^{22}$. Ante ello, Madrid se volvió cada vez más receloso al envio de todo tipo de mensajes y el Ministro ante este gobierno, Suma, le avisó a su Ministerio de Exteriores o Gaimushô de "ser más cuidadoso con el tratamiento de los mensajes, ya que no queremos poner al gobierno español en un compromiso" ${ }^{23}$.

Si bien las presiones para cualquier tipo de labor humanitaria son normales en cualquier momento, y más aún en tiempo de guerra, el fuerte predominio de los fines políticos sobre los humanitarios lastró en buena medida esa defensa de los nacionales japoneses. Tanto Tokio como Madrid buscaban por medio de la labor de representación victorias políticas para sus propios propósitos; pero si bien estos propósitos tuvieron ciertos puntos en común al comenzar la guerra, fueron desapareciendo según continuó el conflicto. Así, mientras que Tokio usó constantemente los presuntos maltratos de los internados en los Estados Unidos para propósitos propagandísticos internos, Madrid se desentendió cada vez más de esa tarea de potencia protectora por la necesidad de mostrar a los aliados una posición independiente frente a la de los países del Eje.

Ya desde el verano de 1942 se puede comprobar que, ni Tokio estaba contento con la actuación de los españoles, ni los españoles tenían muchos deseos en gastar fuerzas defendiendo nipones. Tokio necesitaba cada vez más noticias sobre maltratos a japoneses y los españoles escasamente les ayudaban, entre otras razones por una fuerte campaña de prensa contra España en los países americanos por encargarse de esos intereses. Con ello, el interés que pudiera tener el Ministerio de Exteriores españoles reducido a su espíritu de profesionalidad, sin ninguna recompensa adicional en un plano político. En junio de 1942 encontramos las primeras quejas japonesas sobre las tareas de España, con ocasión del primer intercambio de civiles entre los Estados Unidos y Japón, ya que algunos de los seleccionados por Tokio para regresar prefirieron permanecer en territorio americano. Este rechazo de sus propios súbditos motivó variaciones en las listas de repatriados y, en consecuencia, un fuerte enfado

22 El gobierno envió mensajes por medio de Madrid. AMAE, Leg. 1134, exp. 6. Mensajes de los antiguos Embajadores a las colonias en Brasil, Perú y a los internados en los Estados Unidos desde Colombia y Costa Rica. Anexo a la Nota de la Legación de Japón al Mae, Madrid, 12-XII1942. Sobre la conciencia de los hispanos de ser utilizados para sus propios fines por los internados, CORBETt, op. cit., pág. $\$ 17$.

23 Fue a propósito de una resolución de la Dieta Japonesa de 14-IV-1943 enviando un «mensaje de simpatia y esperanza" para los nacionales en Occidente. MS de 18-IV-1943. Tel de Suma a Gaimushō, Madrid, 14-IV-1943. En MS de 18-IV-1943. 
de Tokio. Sobre ello, el ministro japonés de Exteriores, Tōgō aseguraba a su ministro en España, Suma Yakichirō, que "todo el mundo" en Japón estaba muy preocupado, porque algunas de las personas que ese gobierno estaba interesado en repatriar y que habian sido incluidos en anteriores listas, no estaban incluidos en la definitiva. Acababa el telegrama señalando: "Este Embajador Español en Washington [Cárdenas]... parece que ha tomado las explicaciones premeditadas y engañosas de los americanos en su significado literal. Esto lo encontramos difícil de creer. Ha sido incapaz de dar alguna buena razón por tal actitud de su parte» ${ }^{24}$.

Las quejas japonesas contra la actuación española se incrementaron cuando el primer barco de intercambio llegó a territorio japonés y los ex-internados pudieron hablar sobre las condiciones de la detención. El 16 de septiembre de 1942, el Ministro de Exteriores Tōgō envió un telegrama circular a las representaciones japonesas dando cuenta de las informaciones de estos funcionarios, en las que explicaba que habían sido sometidos a "tratamientos inhumanos". Las acusaciones incluian "terrorización», robo, tortura, violación, malas condiciones de vida en los campos de internamiento, azotes, extorsión y saqueo de los almacenes japoneses, concluyendo que los cargos "muestran la falsedad de los informes del Embajador Español, quien nos asegura que todo está yendo bien» ${ }^{25}$.

Es difícil saber lo que había de cierto en las manifestaciones de los regresados a Japón y hasta qué punto estas acusaciones fueron producto de la tensión de los tiempos de guerra. El Ministro japonés acusó a los españoles, también, de ser escasamente cuidadosos y precipitados en sus investigaciones y en sus negociaciones con el gobierno estadounidense y buena parte de estas quejas había de estar motivada por esas necesidades propagandisticas sobre el carácter inhumano de los norteamericanos hacia los japoneses ${ }^{26}$. Quizás lo mas interesante es que se señalara el ejemplo de Suiza, que tenía varios ayudantes dedicados a cuidar de los intereses extranjeros en Japón, al sugerir que probablemente los españoles necesitaran emplear ayuda extra para su trabajo de protección.

A partir del mes de agosto de 1942 el Conde de Jordana pasó a ocupar la cartera de Exteriores en sustitución de Ramón Serrano Suñer, comenzando a

24 Tel de Tōgō a Suma en MS de 15-V1-1942. La nota de la Legación japonesa al Mae, fechada en 22-VI-1942. La respuesta de Washington, fechada el 19-VII-1942, indicaba que de las 53 personas sobre las que se inquiria sobre porqué se habian descolgado de las listas, 21 de ellos habian rehusado por nota escrita el querer abandonar el pais, 9 irian en el siguiente intercambio, etc. AMAE, Leg. 1134, exp. 7.

25 MS de 22-1X-1942

26 Tel de Tōgō a Suma, en MS de 7-VI-1942. 
dar su giro hacia la neutralidad precisamente en relación con Japón ${ }^{27}$. Aunque las ideas podían ser parecidas a las de Serrano Suñer, la actitud de Jordana tenía un talante radicalmente diferente y menos comprometida abiertamente con los países del Eje. Varios hechos muestran un cambio, como es el caso del espionaje: aunque autorizó aparentemente a que siguiera funcionando, afirmó que siempre negaria conocer su existencia, lo que a medio plazo acabó con su funcionamiento. Después, el 29 de octubre de 1942, el embajador nipón Suma Yakichirô recibió la primera nota verbal española "con un lenguaje fuerte" protestando por el tratamiento a los súbditos hispanos en Filipinas y con ello pudo darse cuenta cómo el cambio de ministro al frente del Ministerio afectaría a los aspectos más importantes de las relaciones hispano-japonesas: «Bien, nosotros ya no tenemos más a Suñer, hemos de tratar con un nuevo ministro [Jordana] que tiene carta blanca, y si no hacemos por adaptarnos a él, no solamente dejará de ayudarnos a representar los intereses japoneses, sino que también cesará en permitir a su país ayudarnos en el espionaje» ${ }^{28}$.

Y si bien la etapa de Jordana en el Ministerio de Exteriores atenuó la amistad con el Eje, no aumentó el interés por cumplir con la labor humanitaria. Peor aún, lo disminuyó al ser cada vez más sensible el gobierno español a la mala imagen que le reportaba ese lazo, siquiera humanitario, con Japón. Las dificultades políticas superaban con mucho a las de otro tipo y José María Doussinague, recién nombrado número dos del MAE como Director General de Política Exterior, le comentaba a un miembro de la Legación japonesa, «(...)las relaciones con México son muy malas y con Cuba, muy tensas. Nicaragua ni siquiera nos reconoció para representar los intereses de Alemania e Italia, lo que fue vergonzante para nosotros" ${ }^{29}$. Y si Doussinague lo sugirió, el Embajador en Washington, Cárdenas, se lo dijo directamente al Ministro japonés Suma durante una visita a Madrid: "La representación por España de los intereses japoneses ha sido objeto de toda clase de desprecios y está valiendo a la Embajada de España su popularidad". La posición cada vez más pro-estadounidense no fue privativa de Madrid y también Chile y Argentina acabaron rompiendo relaciones con Japón ${ }^{30}$.

27 Sobre ello, ver mi Tesis Doctoral Relaciones Hispano-Japonesas 1937-1945. Madrid, 1993.

Tel de 7-VI-1942. Idem.

Conversación de 14-XI-1942, en MS de 19-XII-1942.

Chile to hizo en diciembre de 1942 y Argentina fue el último pais, el 26 de enero de 1944 
En definitiva, la marcha política de las relaciones mutuas no favoreció el buen cumplimiento de la labor humanitaria, aunque ésta se siguió desarrollando. Las detenciones y los presuntos malos tratos de súbditos japoneses en los Estados Unidos siguieron siendo uno de los asuntos más espinosos y los españoles informaron de conflictos cuando éstos aparecieron, como uno que ocurrió en el "Centro de Realojamiento Manzanares» en diciembre de 1942, en el primer aniversario del estallido de la Guerra, ${ }^{31}$ o sobre una huelga de los japoneses internados en el "Centro Poston" (Arizona), ${ }^{33}$ pero también cooperaron para allanar las sospechas o, como en el último caso, echaron la culpa de los disturbios principalmente a los Issei o japoneses emigrados de primera generación. El Campo Lake Tule, que desde el verano de 1943 fue convertido en el centro receptor de los súbditos japoneses potencialmente más problemáticos, llegó a ser el asunto más problemático en la representación de los intereses japoneses en los Estados Unidos y en ello parece que los españoles trataron de ayudar a los norteamericanos, aunque también intentando defender los intereses japoneses de alguna forma ${ }^{33}$.

La necesidad propagandistica japonesa de profundizar en la utilización propagandística de los malos tratos continuó. En el otoño de 1943, el Ministro de Exteriores Shigemitsu instruyó a Suma informar al Gobierno español que estaba fuertemente decepcionado por el tratamiento dado a los súbditos japoneses en el hemisferio occidental: "Sus afirmaciones [las de los informes españoles] han incitado al pueblo y pueden muy bien llegar a ser una cuestión para el Consejo de Ministros" ${ }^{34}$. Poco después pidieron un informe urgente sobre las condiciones de internamiento al embajador español en Washington, explicando que «la opinión pública en casa se esta poniendo tensa" ${ }^{35}$. Sin embargo, el comienzo del fin de la hegemoría militar de Japón y del Eje aislaban cada vez más a este país y Tokio no pudo ir más allá en sus quejas contra España, habiendo de resignarse a pedir a España que también representase sus intereses en Chile en octubre de 1942, cuando ya se preveía la ruptura de

\footnotetext{
31 AMAE, Leg. 1134, exp. 3. Nota del Jefe de la Oticina de Protecciones a la Legación de Japón, Madrid, 8-X|1-1942.

32 Ibid. de $27-X I-1942$

33 Los problemas en este campo bloquearon cualquier tipo de acuerdo para envio de alimentos desde Estados Unidos a los prisioneros detenidos por Japón. Archivo de Presidencia de Gobierno, Sección Jefatura del Estado, Leg. 5, exp. 2.4. Tel de Méndez Vigo a Mae, Tokio, 3-l-1945.

34 MS de 26-X1-1943.

35 Tel de Shigemitsu a Suma de 7-XII-1943, en MS de 15-XII-1943. También, el Gaimushō había pedido al Embajador Tomii en Buenos Aires que enviara una persona apropiada a Brasil a estudiar las condiciones de sus nacionales. Idem. Ver también MS de 20-11-1943.
} 
relaciones, ${ }^{36}$ a lo que España se negó ${ }^{37}$. Tokio nunca respondió a los informes españoles que se referían a condiciones aceptables en esos Campos de Realojamiento ${ }^{38}$ y continuó usando el presunto maltrato a estos internados como un arma propagandística. Para ello, algunos informes españoles también fueron usados por el gobierno japonés para especificar cuáles eran las quejas sobre la mejora de condiciones, como es el caso del uso de la policía militar ${ }^{39}$.

Fue en el año 1944 cuando la cooperación política entre Japón y España se cortó definitivamente y la tensión de las relaciones llegó incluso a la opinión pública por medio del diario Arriba, en un acto muy significativo para el régimen franquista ${ }^{40}$. Un dato que aparece clave en el cambio de esta posición española fue, en enero de este año, la presunta confirmación en Estados Unidos de la llamada "Marcha de la Muerte» en Filipinas, tras la rendición en Bataan por las tropas norteamericanas y Filipinas, de enero de 1942. Miles de estos soldados habian muerto, tras haber sido hechos prisioneros, a causa de las condiciones en las que les hicieron llegar al centro de detención ${ }^{41}$.

Ello hubo de ser clave para que Madrid instruyera a sus Ministros en Tokio y en Berna, por primera vez en la guerra, para presionar al gobierno japonés con el objeto de conseguir que sus prisioneros en el Asia Oriental fueran visitados por los representantes suizos "y con ello quitar argumentos a la campaña contra España» ${ }^{42}$.

Finalmente, las relaciones se deterioraron según el curso de la guerra favorecía cada vez más a los Estados Unidos y España acabó utilizando en el mes de marzo de 1945 la renuncia a la defensa de los intereses japoneses, como paso previo a una ruptura de relaciones (12 de abril

36 Tel del Ministro de Exteriores (Tani Masayuki) a Yamagata (Ministro en Chile). En MS de $31-X-1942$.

37 AMAE, leg.1562, exp.10. Informe de la Oficina Central de Protecciones del Mae, Madrid, $28-X-1942$.

38 Ver AMAE, Leg. 1562, exp. 10. Despacho 32 de Méndez Vigo a Mae, Tokio, 9-V-1944 y telegrama de 11-VIII-1944.

39 Ver la nota japonesa de 18 de abril de 1944 y la respuesta estadounidense de 10 de agosto en Ota ICHIRO, op. cit., Vol. 24, págs. 503-513. Sobre ello, también en CorbetT, págs. $129-135$. En Foreign Relations of the United States (FRUS), 1945, Vol. IV. Carta 773 de Encargado en Suiza, Huddle, al Secretario de Estado, Berna, 3 de febrero de 1942, sobre las peticiones japonesas de información a España de prisioneros de guerra y localización de campos de prisioneros. pág. 320 .

40 "En las Filipinas, la Lengua española ha sido relegada por el Japonés y el Tagalo". Arriba, Madrid, 12-II-1944. Después de este periódico, hizo lo mismo el resto de la prensa.

41 AMAE, Tel 1562, exp. 12. Tel de Cárdenas a Mae, Washington, 28-1-1944.

42 AMAE, Leg. 1562, exp. 12. Tel de Jordana a Ministro en Berna, Madrid, 8- /1-1944. 
de 1945) y posiblemente a una declaración de guerra, alegando Madrid masacres (ciertas) de españoles en las Filipinas.

La conclusión principal del presente trabajo sería saber si los españoles cumplieron correctamente su función, pero ello es extremadamente difícil. No podemos comprobar lo que los diplomáticos vieron o escucharon, ni saber a ciencia cierta si quisieron plasmarlo en los informes. La documentación encontrada en el Archivo del Ministerio de Exteriores tiende a mostrar que las quejas japonesas tenían algo de razón y que la tarea de protección nunca fue llevada muy intensamente en el caso japonés, aunque quizás sí en los casos alemán o italiano. Aparece claro, no obstante, que faltó el apoyo institucional para alentar una labor tan complicada; no tenemos constancia de ninguna orden desde Madrid animando a los diplomáticos $\mathrm{y}$, por otro lado, sus actividades fueron fuertemente escrutadas, al menos en los Estados Unidos, por ese temor al uso de estos funcionarios como un canal para actividades de inteligencia ${ }^{43}$. Por otro lado, los españoles habian de saber bien esas sospechas que recaían sobre ellos, aunque sólo se quisieran dedicar a la labor humanitaria.

Entre los factores positivos, habria que destacar que el papel de España parece haber sido importante para la aceptación por Japón de un segundo intercambio de civiles con Estados Unidos. Las dificultades fueron mayores que en el primer caso, por las demandas de otros gobiernos con sus propios detenidos japoneses, por la decisión de Franklin D. Roosevelt de prohibir más intercambios de civiles y por la fría respuesta japonesa ${ }^{44}$. No obstante, es posible que el Embajador Cárdenas influyera decisivamente. El 26 de abril de 1943 prometió usar toda su influencia, por medio de Madrid y del Ministro en Tokio, Santiago Méndez de Vigo, para lograr un segundo intercambio y poco después, el 1 de mayo, llegó el primer signo de un cambio en la posición japonesa que acabó con el intercambio que finalizó con la llegada del buque Gripsholm a Nueva York con los evacuados, el 2 de septiembre de $1943^{45}$. Además de esta función

43 Ver WEGLYN, op. cit., p. 301 y GUTIËRAEZ, José LuIS. "Madrid, Ileno de espías", en Cambio 16, (1-X-1978), págs. 15-17. También MS de 10-1-1943, Informe de Suma de 4-1-1943 desde Madrid.

44 Ver Tel de Tani a Suma de 22 de febrero de 1943, en MS de 21 de marzo de 1943.

45 CoRBem, op. cit., pág. 89. Tambièn ver Tel de Tani al Ministro en Portugal, Tokio, 16-IV-1943, en MS de 24-IV-1943. Sobre una posible repatriación de descendientes brasileños a cambio de ciudadanos norteamericanos en este intercambio, Public Record Office (PRO), Foreign Office (FO), Serie 371, exp. 26557 (W9372/151/49). Tel de Broadmead a FO, Rio de Janeiro, 24-V-1943. Otras comunicaciones por medio de España en id., exp. 36577. Sobre el intento de usar para fines propagandísticos a los intercambiados, para que hagan declaraciones favorables a Japón, ver Tel del Cónsul General de Pekín a Nankin, 2-IX-1943, en MS II-IX-1943. En AMAE, Leg. 1562, exp. 10, tel 182 de Méndez Vigo a Mae, Tokio, 12-IX-1942 para intentar que el agregado comercial francés fuera incluido. 
que no estaba prevista, España fue solicitada por Japón para otros asuntos, como protestar al gobierno británico por el tratamiento a los japoneses en la India o por el Manchukuo para solicitar que se encargaran de la representación de los escasos intereses en Italia ${ }^{46}$. Por su parte, Madrid solicitó a Japón interceder para saber el paradero de un alférez de la División Azul en la Unión Soviética ${ }^{47}$. No obstante, hemos visto con anterioridad una cierta decepción nipona. Cuando encargaron esta tarea esperaban una "neutralidad benevolente" hacia ellos y, sin embargo, se puede decir que los españoles, si la tuvieron, fue a favor de los norteamericanos, no de los japoneses ${ }^{48}$. La documentación consultada confirma la impresión que quisieron dar los españoles en Estados Unidos de intentar evitar cualquier clase de represalia en los territorios japoneses ${ }^{49}$. En ningún momento la defensa de los derechos de los japoneses en los Estados Unidos provocó un serio problema en las relaciones hispano-norteamericanas. Es más, al contrario que con los suecos, la División Especial encargada de los internados encontró al gobierno español «un firme y leal amigo", " ${ }^{50}$ con los mismos objetivos que el Departamento de Estado.

Resulta difícil discernir si las críticas japonesas fueron motivadas principalmente por el momento especialmente tenso de la Guerra o si tenían una justificación basada en hechos reales. España, sin una tradición clara de neutralidad como Suiza, no tenia ganado el respeto en una labor como la defensa de los intereses de otras naciones y su fuerza moral para hacer valer sus puntos de vista fue escasa ${ }^{51}$. La falta de algún conflicto en este sentido puede sugerir que quizás no se llevó a cabo con la suficiente energía una

46 Comunicación de Tógō al Ministro en Berna, 14-IX-1942, en MS de 25-IX.1942. AMAE. Leg. 1562, exp. 10 y Carta del Ministro del Manchukuo en España, Kwan Makumaru, a Mae, Madrid, 22-X-1943.

47 Archivo de la Embajada Española en Tokio (AEET). Tel 46 de Jordana a Legación en Tokio, Madrid, I-IV-1943. Los japoneses sugieren que se actúe por intermedio de otro país, como Suecia.

48 Un funcionario trabajando en la División Especial del Departamento de Estado, Kelley, aseguraba sobre el consul en San Francisco. Fernando de Amat, y sobre su ayudante, Carlos Martín: "Si seguimos poniendo las cartas sobre la mesa con estos hombres, sean las cartas buenas o malas, creo que tendremos su apoyo". Entrevista en Corbett, op. cit., pág. 45. Ver también MS de 14-IV-1943 y $27-||-1944$

49. Juan de Molina, miembro de la Embajada Española en Washington, afirmaba, en agosto de 1942, a un funcionario notteamericano, que él y sus colegas estaban intentando evitar una cadena de represalias por despecho y que "todos sus informes a los japoneses[...] estaban destinados a evitar cualquier cosa que pudiera conducir a represalias". En Corbett., op. cit., pág. $† 15$.

50 CORBETt, op. cit., pág. 137.

51 Aparentemente a los españoles les era muy dificil sobreponerse a las críticas contra los presuntos malos tratos de los japoneses. AMAE, Leg. 2910, exp. 12. Despacho 97 de Cárdenas a Mae. Washington, 27-11-1945. 
tarea que debia de llevar a continuas tensiones con los funcionarios del gobierno estadounidense: «El consenso de aquellos que trataron con los españoles fue que representaron los intereses escrupulosamente, aunque no fueran tan enérgicos como los suizos» ${ }^{52}$.

La estrecha relación de esta labor humanitaria con las dificultades políticas del régimen de Franco se revela claramente en una nota de prensa aparecida el 2 de noviembre de 1942, poco después de la llegada de Jordana al Ministerio de Exteriores por segunda vez. En su texto, la referencia a los problemas tenidos en América Latina por la relación con Japón es clara: «ante la reiteración de la campaña que en algunos países de América viene desarrollándose desde hace meses contra los representantes de España por su actuación, especialmente a partir de la entrada de Japón en la guerra, se hace indispensable definir cual es la verdadera actitud [...]" 53. La nota achacaba a los «Rojos» esa presunta campaña antiespañola y finalizaba explicando el carácter de la protección a los intereses japoneses. El propio Ministro nipón en Madrid se daba cuenta de la fragilidad de la decisión española de representar los intereses españoles y recomendaba censurar, tanto los artículos demasiado severos en los periódicos japoneses hacia los paises americanos, puesto que complicaba las negociaciones para futuros intercambios, como cualquier expresión de insatisfacción a la forma en que los funcionarios españoles locales estaban llevando la tarea ${ }^{54}$. Además, en esta labor hubo de influir el odio racial que caracterizó la Guerra del Pacífico trente a la Europea, y esa opinión la expresa el propio Embajador Cárdenas a su colega Suma durante una visita a Madrid: "los americanos sienten más animosidad hacia Japón de la que sienten hacia Alemanias 55.

Las motivaciones políticas relajaron el sentimiento de obligación de España hacia Japón tras el compromiso de protección adquirido en diciembre de 1941 por Ramón Serrano Suñer pero, más allá de estas dificultades, algunos datos señala que España dejó de cumplir sus obligaciones. Así, permitió incumplir uno de los artículos de la Convención de Ginebra, el 31, cuando en la vecindad del Campo de Internamiento de Poston (Arizona), fue creado una fábrica de redes de camuflaje para emplear tanto a

CORBETT, op. cit., págs. 46 y 67-68.

AEET. Circular del Ministerio de Asuntos Exteriores. Firmado: Doussinague. Madrid, 9-XI-1942.

54 Suma a Tógō, Madrid, II-VII-1942, en MS de 14-VII-1942.

55 Conversación Cárdenas-Suma, celebrada en Madrid en 18-V-1943. En Tel de Suma a Shigemitsu, MS de 2-VI-1943. Para el estudio del carácter racial de la Guerra del Pacífico, ver DOWER, John W, War Without Mercy. Race \& Power in the Pacific War, Nueva York, Pantheon, 1986. 
japoneses-americanos como a súbditos nipones, lo que forzó a los internados a escoger si trabajar o no en una labor relacionada con la guerra, causando enfrentamientos entre ellos ${ }^{56}$. También, en el caso de los muertos por disparos de los vigilantes al intentar escapar de los campos de internamiento, se asegura que los españoles ayudaron en las investigaciones para evitar las sospechas japonesas sobre si esos disparos habían sido por antipatía racial ${ }^{57}$.

La expresión del descontento nipón la podemos encontrar no sólo en los períodos finales de la guerra, sino desde el verano del año 1942. Y quizás la desesperación nipona ante el desentendimiento español se puede percibir claramente en estos momentos, cuando se exploró una alternativa a la labor española buscando la ayuda del Vaticano. El 25 de julio de 1942, el Ministro de Exteriores Tōgō comunicó a su representante ante la Santa Sede, Harada Ken: "Lo que nosotros esperamos hacer es preguntar al Papa no solamente sobre el intercambio de noticias sobre nuestros súbditos detenidos, sino también investigar las condiciones de los súbditos japoneses en general, particularmente en los Estados Unidos" ${ }^{58}$. Los japoneses ofrecieron a cambio pasar información a Pio XII, por medio del representante del Vaticano en Tokio, informes sobre prisioneros en sus territorios ocupados y particularmente de los católicos ${ }^{59}$. Finalmente, el Papa se ofreció a "asistir personalmente» en llevar a cabo un «intercambio de información en relación con los prisioneros de guerra y con los civiles internados en las naciones beligerantes" ${ }^{60}$. Las instrucciones enviadas poco después a Harada desde Tokio son claras de la opinión japonesa: "Ya que parece dificil obtener informes precisos sobre los colonos japoneses en el interior del país por medio de la potencia que está representando nuestros intereses [España], nos gustaría tener un informe certero y detallado por medio del Vaticano" ${ }^{61}$. España fue puenteada. Los intereses políticos predominaron siempre sobre los humanitarios.

\footnotetext{
56 Ibíd, pág. 128.

57 Ibíd. pág. 128. Ver también pág. 135 sobre rechazo de responsabilidad para casos de traslados.

5. Tel de Gaimushō a Embajador en el Vaticano, Tokio, 23 de julio de 1942, en MS de 29 de julio de 1942.

s. MS de 4-V\|II-1942.

60 MS de 25-VIII-1942

6. MS de 17-IX-1942. Ver FRUS, vol. III. Carta 53 de Cicognani [Delegado Apostólico en Washington] al Secretario de Estado Welles, 1-VII-1943. Sobre ello, también, “La Oficina de Intormación del Vaticano pone en comunicacion a los prisioneros con sus familiares", Mundo, núm. 216, 26-V'l-1944.
} 